\title{
SISTEM INFORMASI GEOGRAFIS BERBASIS WEB DIGITASI PERSIL BANGUNAN
}

\author{
Arief Susanto $^{1)}$ \\ ${ }^{1)}$ Program Studi Teknik Informatika Universitas Muria Kudus \\ e-mail: ariefpj1@gmail.com ${ }^{1)}$
}

\begin{abstract}
Abstrak
Geographic Information Systems ( GIS abbreviated as Geographic Information System) is a specialized information system that manages data having spatial information. Most to process data in the form of GIS data are still many who use desktop application or can only run on one computer while the more advanced development requires us to produce information more easily is to develop a GIS online (via the Internet) and can be accessed Anywhere You. This application is designed using DFD modeling and created using the programming language PHP with MySQL database as well as utilizing Google Map API . As well as to facilitate the collection of data by the field of local government development. Moreover, the existence of GIS aims to help local governments in the search for building plots parcels and ownership of data previously not been structured to be more structural and facilitate spatial data collection .
\end{abstract}

KeyWords : GIS, System, Persil.

\section{PENDAHULUAN}

Perkembangan suatu usaha atau kegiatan berawal dari kesediaan data yang ada guna pengambilan informasi. Nilai dari informasi juga harus tepat, cepat dan akurat sehingga keputusan yang diambil dapat menjadi tolak ukur keberhasilan kegiatan yang akan dilakukan.

Di lingkungan pemerintah daerah, ketersediaan data telah dilakukan oleh masingmasing satuan kerja. Data ini terbagi di masingmasing instansi terkait sesuai bidang kerjanya. Data yang disajikan biasanya berupa data kuantitatif yang direkap dari turunan satuan kerja tersebut untuk dapat disajikan ke instansi terkait baik secara horizontal maupun vertikal. Data yang tersaji selanjutnya akan direkap oleh instansi yang lebih tinggi untuk disajikan sebagai data statistic dan berfungsi untuk pengolahan informasi bagi pengambilan keputusan. Kendala yang muncul, seringkali data yang disajikan selalu dilakukan secara mendadak sehingga kesiapan instansi terkait mengalami kendala dalam penyajian dan perekapannya. Kondisi ini menyebabkan pegawai terkait melakukan jalan pintas dengan memanipulasi data lama dengan perhitungan perkiraan atau menggunakan data lama seadanya. Hal ini menyebabkan data statistic yang tersaji kurang akurat. Antara data dari instansi yang terendah ke instansi diatasnya seringkali tidak sinkron. Kondisi ini menyebabkan dampak keputusan yang diambil menjadi tidak akurat.

Untuk memperoleh data yang akurat, solusi terbaik adalah dengan pengambilan data langsung dari instansi terendah di lingkungan pemerintahan daerah. Instansi terendah dalam hal ini adalah pemerintahan desa / kelurahan. Desa merupakan tempat koordinasi antara masyarakat secara langsung, dan instansi ini yang langsung bernteraksi dengan data dasar. Untuk dapat mengetahui lokasi dan letak data dasar ini secara riil, maka diperlukan pemetaan asset / data terkait yang ada di lingkungan pemerintahan desa.

Guna mengetahui lokasi dan keberadaan asset tersebut diperlukan sistem pengolahan data berbasis GIS (Geografis Information System). Penggunaan GIS bersama dengan teknik pemodelan komputer dapat memperluas cakupan dari proses analisa dan proses pengambilan data dasar guna menyajikan informasi bagi pengambilan keputusan.

Data persil adalah bentuk data dasar yang terlihat didalam sistem pemetaan. Persil ini bisa dalam bentuk bangunan baik rumah, kantor dinas, sekolah, tempat ibadah, yayasan sosial dan pertokoan. Dari data persil ini, merupakan tempat bernaung masyarakat dan asset-aset yang nantinya akan diolah di dalam data dasar.

Berdasarkan latar belakang tersebut, penulis akan mengangkat permasalahan tentang persil bangunan dengan judul "Sistem Informasi 
SYSTEMIC

Geografis Berbasis Web Digitasi Persil Bangunan" yang akan menyajikan sebuah data atau informasi yang kompleks kepada masyarakat.

\section{RUMUSAN MASALAH}

Dari uraian latar belakang dan analisa masalah diatas, kendala yang dialami di lingkungan pemerintahan adalah sistem penyediaan data yang tidak akurat, tidak tepat dan tidak cepat. Sehingga diperlukan solusi untuk pendataan dasar dan melakukan rekapitulasi pengolahan data menggunakan lokasi keberadaan data agar diperoleh data riil. Keberadaan data disini dimaksudkan menggunakan letak posisi persil di lingkungan pemerintahan desa dengan pola digitasi dan pendataan sekitar.

\section{TUJUAN PENELITIAN}

Tujuan dari jurnal ini adalah untuk mengimplementasikan sistem informasi geografis pendataan persil bangunan dengan cara mengembangkan teknologi informasi yang tersaji lebih baik dan lebih terstruktur.

\section{TINJAUAN PUSTAKA}

Dalam penelitian Aliyah dengan judul Sistem Informasi Geografis Berbasis Web Mengenai Penyebaran Fasilitas Pendidikan, Perumahan, dan Rumah Sakit di Kota Bekasi, yang bertema sama dengan penelitian Wulandari yaitu dengan sistem informasi geografi. Tetapi penilitian Aliyah bertujuan untuk membangunan sistem informasi geografis berbasis web mengenai penyebaran fasilitas pendidikan, perumahan, dan rumah sakit di Kota Bekasi. Secara umum Web SIG ini dapat membantu masyarakat dan Pemda Kota Bekasi dalam pencarian lokasi fasilitas pendidikan, perumahan, dan rumah sakit yang berada di Kota Bekasi. Hal ini berdasarkan pada hasil jawaban para responden, lebih dari 50\% responden yang menyatakan setuju adanya web SIG ini. [1]

Selain itu penelitian yang dilakukan oleh Esty Rismayanda, pada tahun 2012 yang berjudul Sistem Informasi Geografis Perumahan Kota Banjarbaru Kalimantan Selatan ini hanya mencakup pemetaan untuk perumahan saja dan berbeda dengan penelitian yang dilakukan Wulandari dan Aliyah. Dengan tujuan yang ingin dicapai dari penelitan ini adalah meningkatkan efisiensi dan efektivitas kerja pegawai Dinas Perumahan, Tata Ruang, dan Pengawasan Bangunan wilayah kota Banjarbaru yang ditunjang oleh data yang akurat, yang bukan saja
ISSN: 2460-8092

merupakan data teks, tetapi juga didukung dengan data keruangan (spasial) guna meningkatkan kecepatan dalam hal pengambilan keputusan berdasarkan analisa yang dihasilkan dari masalah yang terjadi di lapangan, seperti meningkatkan monitoring khususnya dalam hal informasi kondisi perumahan yang ada berdasarkan kategori. [10]

Selanjutnya dalam penelitian Wulandari pada tahun 2013 dengan judul Sistem Informasi Geografis Konfeksi Pada Wilayah Kabupaten Kudus Dengan Memanfaatkan Google Maps API, merupakan pemanfaatan teknologi GIS yang dibantu dengan tool Google Maps API. Diantara permasalahan yang dihadapi didalamnya yaitu masih kurangnya pemanfaatan teknologi informasi yang bisa mengkases data disuatu wilayah dengan cepat serta informasi yang disajikan sebelumnya kurang detail , terutama pada data statistic. [13]

\section{LANDASAN TEORI \\ 5.1 Konsep Database Management System}

Satu Database Management System (DBMS) beris satu koleksi data yang saling berelasi dan satu set program untuk mengakses data tersebut. Jadi DBMS terdiri dari database dan set program pengelola untuk menambah data, menghapus data, mengambil dan membaca data. Database adalah kumpulan file-file yang saling berelasi, relasi tersebut biasa ditunjukkan dengan kunci dari tiap file yang ada. Satu database menunjukkan satu kumpulan data yang dipakai dalam satu lingkup perusahaan instansi.

Dalam satu file terdapat record-record yang sejenis, sama besar, sama bentuk, merupakan satu kumpulan entity yang seragam. Satu record terdiri dari field-field yang saling berhubungan untuk menunnjukkan bahwa field tersebut dalam satu pengertian yang lengkap dan direkam dalam satu record. [6]

\subsection{Maps API}

API atau Application Programming Interface merupakan suatu dokumentas yang terdiri dari interface, fungsi, kelas struktur dan sebagainya untuk membangun sebuah perangkat lunak. Dengan adanya API ini, maka memudahkan programmer untuk "membongkar" suatu software untuk kemudian dapat dikembangkan atau diintegrasikan dengan perangkat lunak yang lain. API dapat dikatakan sebagai penghubung suatu aplikasi dengan 
aplikasi lainnya yang memungkinkan programmer menggunakan sistem function. Proses ini dikelola melalui operating system. Keunggulan dari API ini adalah memungkinkan suatu aplikasi dengan aplikasi lainnya dapat saling berhubungan dan berinteraksi. Bahasa pemrograman yang digunakan oleh Google Map yang terdiri dari HTML, Javascript dan AJAX serta XML memungkinkan untuk menampilkan peta Google Map di website lain. [4]

\subsection{Definisi Georapich Information System}

Sistem Informasi Geografis (SIG) merupakan salah satu model sistem informassi yang banyak digunakan untuk membuat brbagai keputusan, perencanaan dan analisis. SIG memiliki perbedaan pokok dengan sistem informasi yang lain. Pada sebuah sistem informasi SIG, basis data atributal adalah fokus dari pekerjaan sistem, sedangkan SIG mengaitkan data atributal dengan data spasial. SIG menjelaskan dimana, bagaimana, dan apa yang terjadi secara keruangan yang diwujudkan dalam gamberan peta dengan berbagai penjelasan secar deskriptif, tabular, dan grafis. Dari kemampuan tersebut, SIG memberi dua jenis model informasi, yaitu dalam bentuk spasial dan deskriptif. Hubungan antara bentuk spasial dan deskriptif dijelaskan secara topologis. SIG adalah sebuah rangkaian sistem yang memanfaatkan teknologi digital untuk melakukan analisa spasial. [3]

\section{KERANGKA PIKIR}

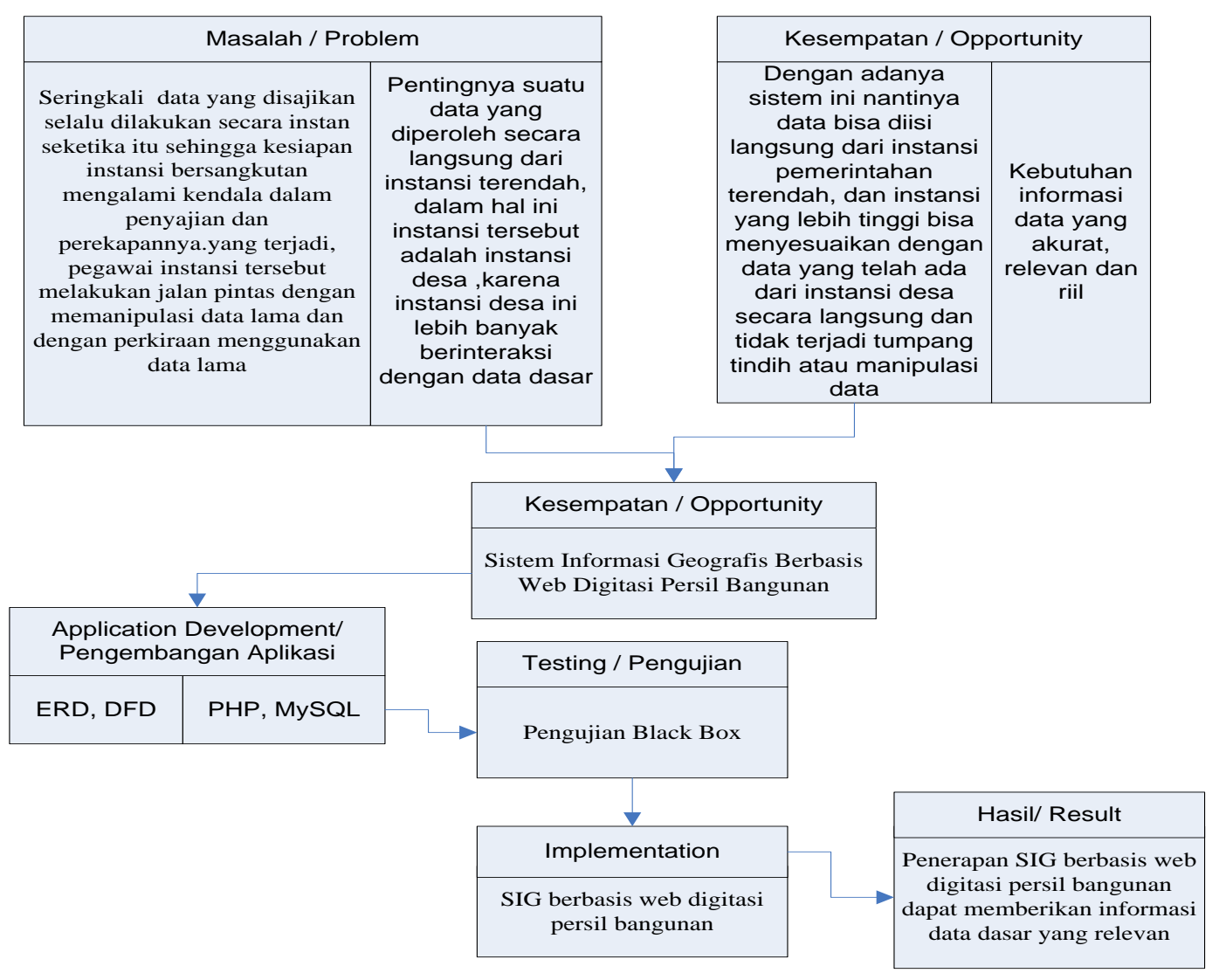

Gambar 1 : Kerangka pikir 


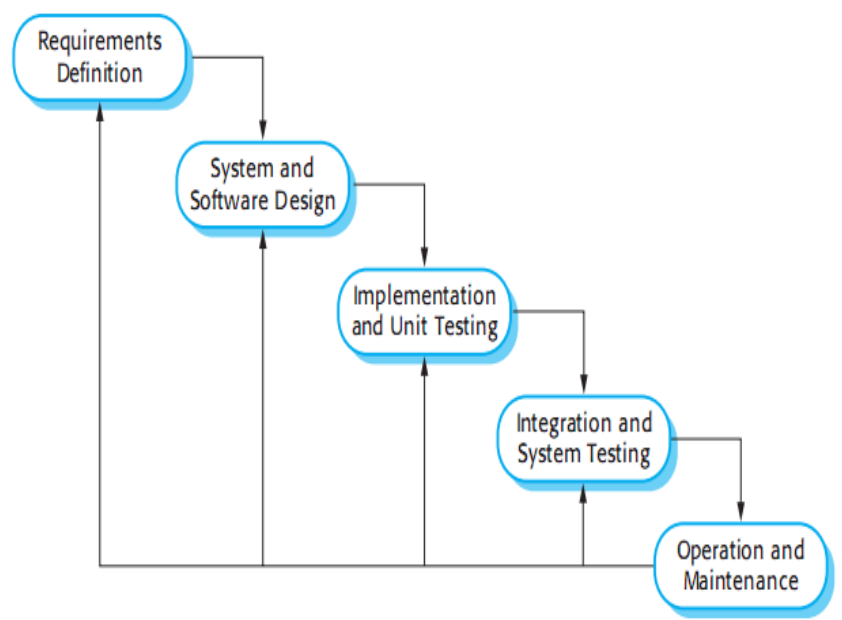

Gambar 2 : Metodologi Waterffall

\section{METODE PENELITIAN}

Metodologi penelitian dapat diartikan ilmu yang dilewati untuk mencapai pemahaman tertentu. Dalam pembuatan aplikasi ini metodologi Waterfall oleh Sammerville Ian 2009. [11] Tahap - tahap pengerjaan aplikasi ini akan digambarkan pada Gambar 2. Metodologi Waterfall, seperti berikut ini :

\section{PEMBAHASAN}

a. Perancangan System

Dalam perancangan system ini, penulis menggunakan DFD (Data Flow Diagram). Yang pertama dilakukan yaitu membuat Context Diagram yang menjabarkan secara keseluruhan di dalam proses sistem ini. Context Diagram berfungsi untuk memetakan model lingkungan yang akan direpresentasikan dengan lingkaran tunggal yang mewakili keseluruhan sistem. Adapun Context Diagram sistem informasi geografis berbasis web digitasi persil yang ditunjukkan pada gambar 3. Context Diagram, seperti berikut :

\section{b. Perancangan Basis Data}

Untuk perancangan basis data sistem informasi geografis berbasis web digitas persil bangunan menggunakan tools Entity Relational Diagram (ERD). Adapun aturan yang terdapat dalam ERD dalam perancangan database, berikut skema ERD yang di tunjukkan pada gambar 4 . ERD, seperti berikut ini :

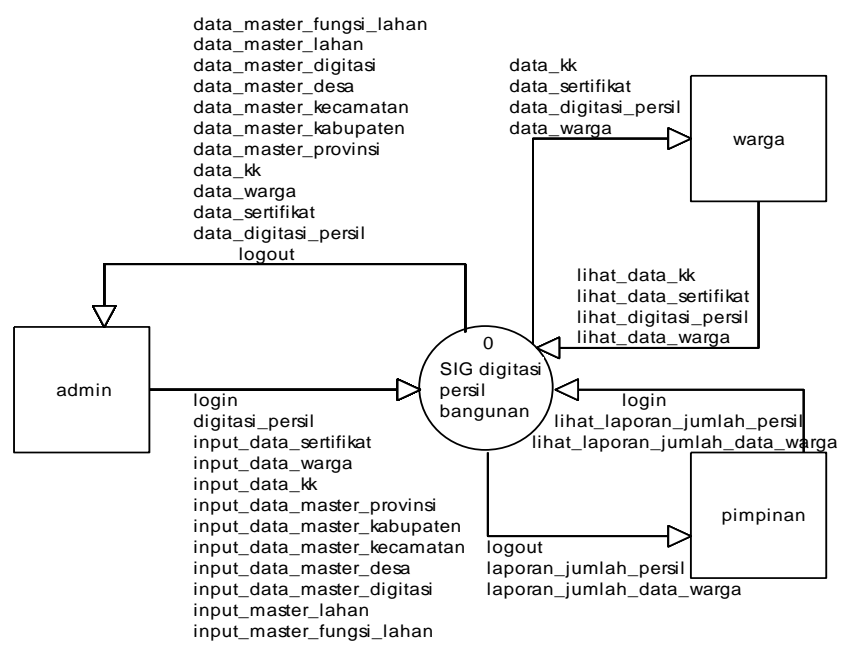

Sistem Informasi Geografis Berbasis Web Digitasi Persil Bangunan

(Arif Susanto) 


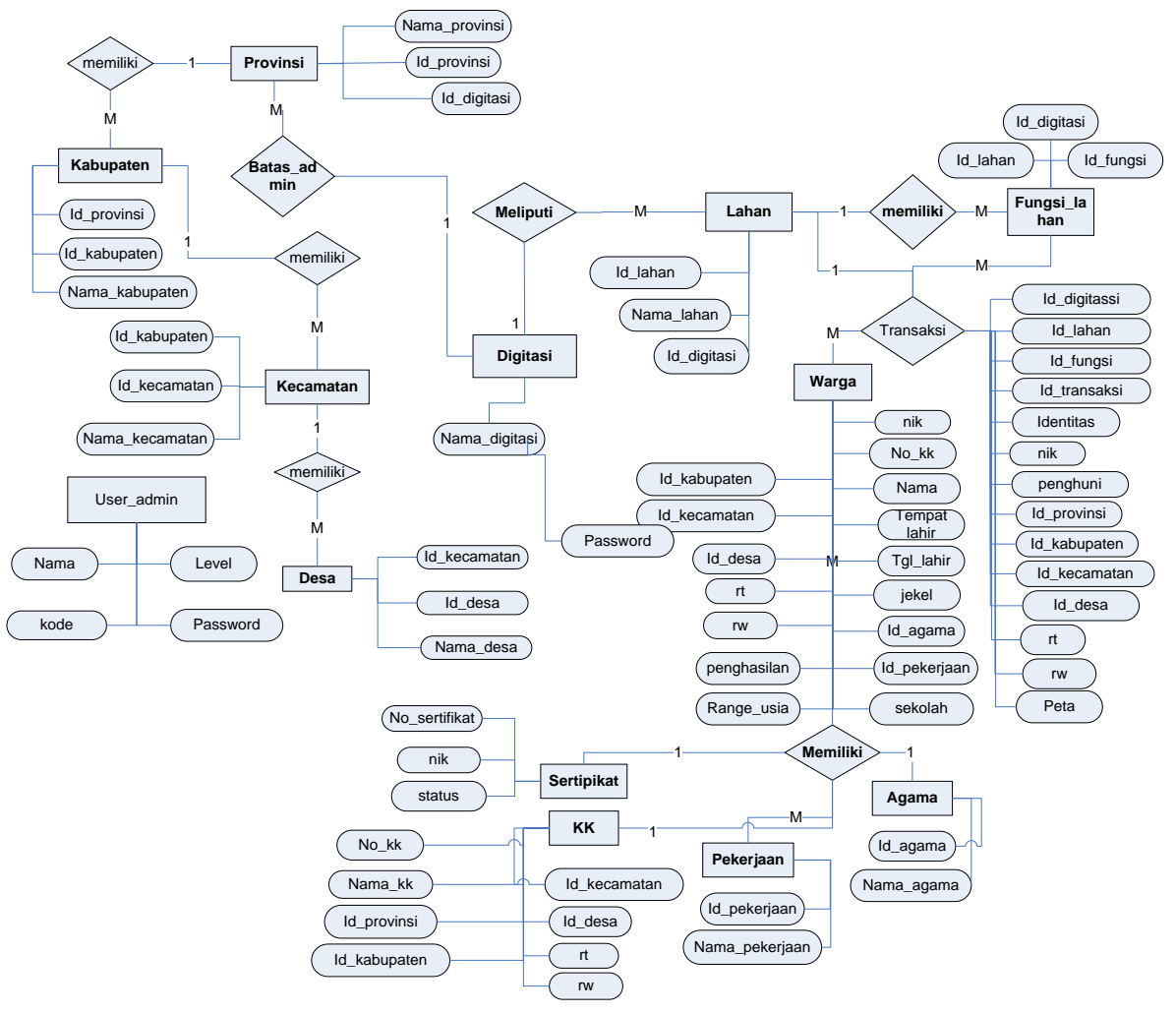

Gambar 4. ERD (Entity Relasionship Diagram)

Dari Skema ERD tersebut diperoleh relasi antar table seperti pada gambar 5 : relasi antar tabel berikut ini:

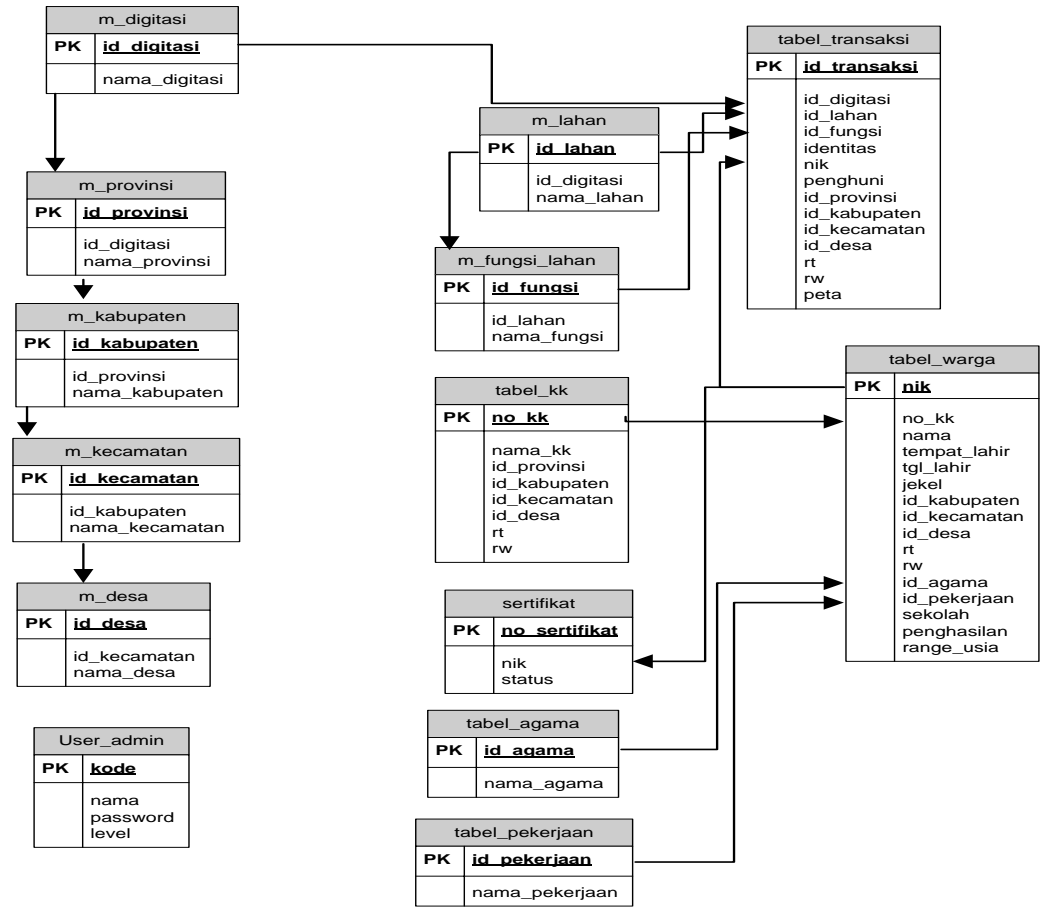




\section{Gambar 5 : Relasi antar table}

Dari hasil perancangan maka dapat diciptakan Sistem Informasi Geografis Berbasis Web Digitasi Persil Bangunan. Berikut merupakan hasil dari capture system yang telah diciptakan, dapat dilihat pada gambar :

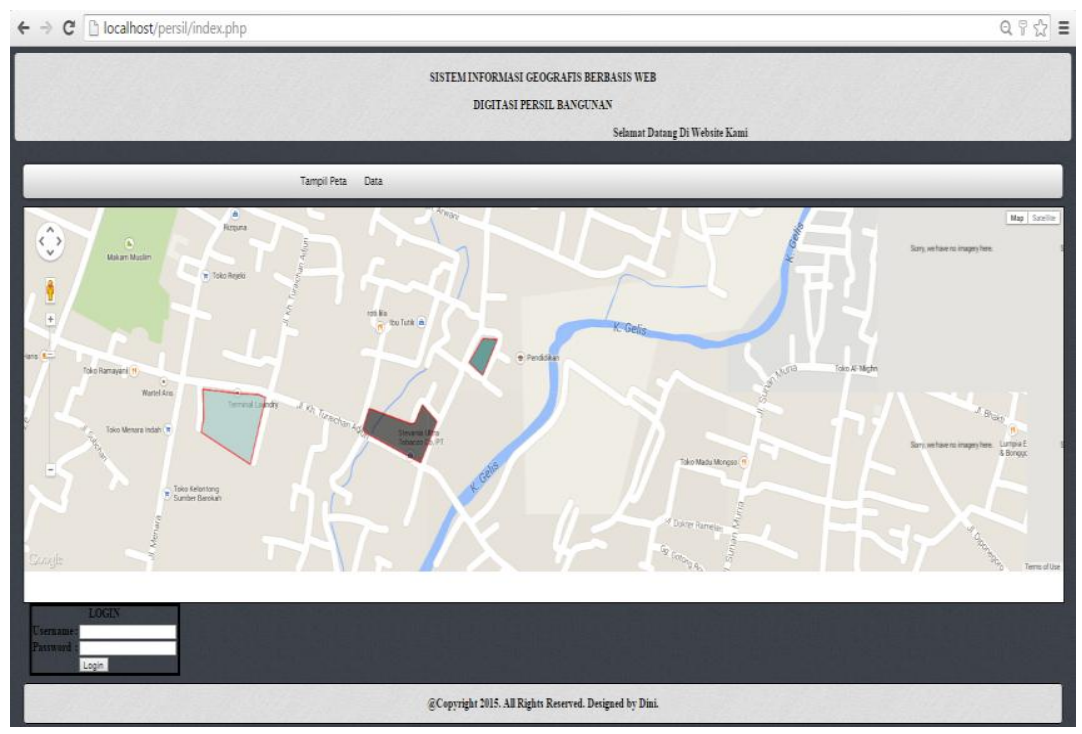

Gambar 6 Hasil Capture system

Dari gambar diatas, dapat dipantau letak dan posisi persil bangunan dan dapat dikelompokkan berdasarkan kriteria sebagaimana gambar 7. Alur Freemind GIS Persil Bangunan dibawah : 
SYSTEMIC

Vol. 1, No. 1, Agustus 2015, 20-28

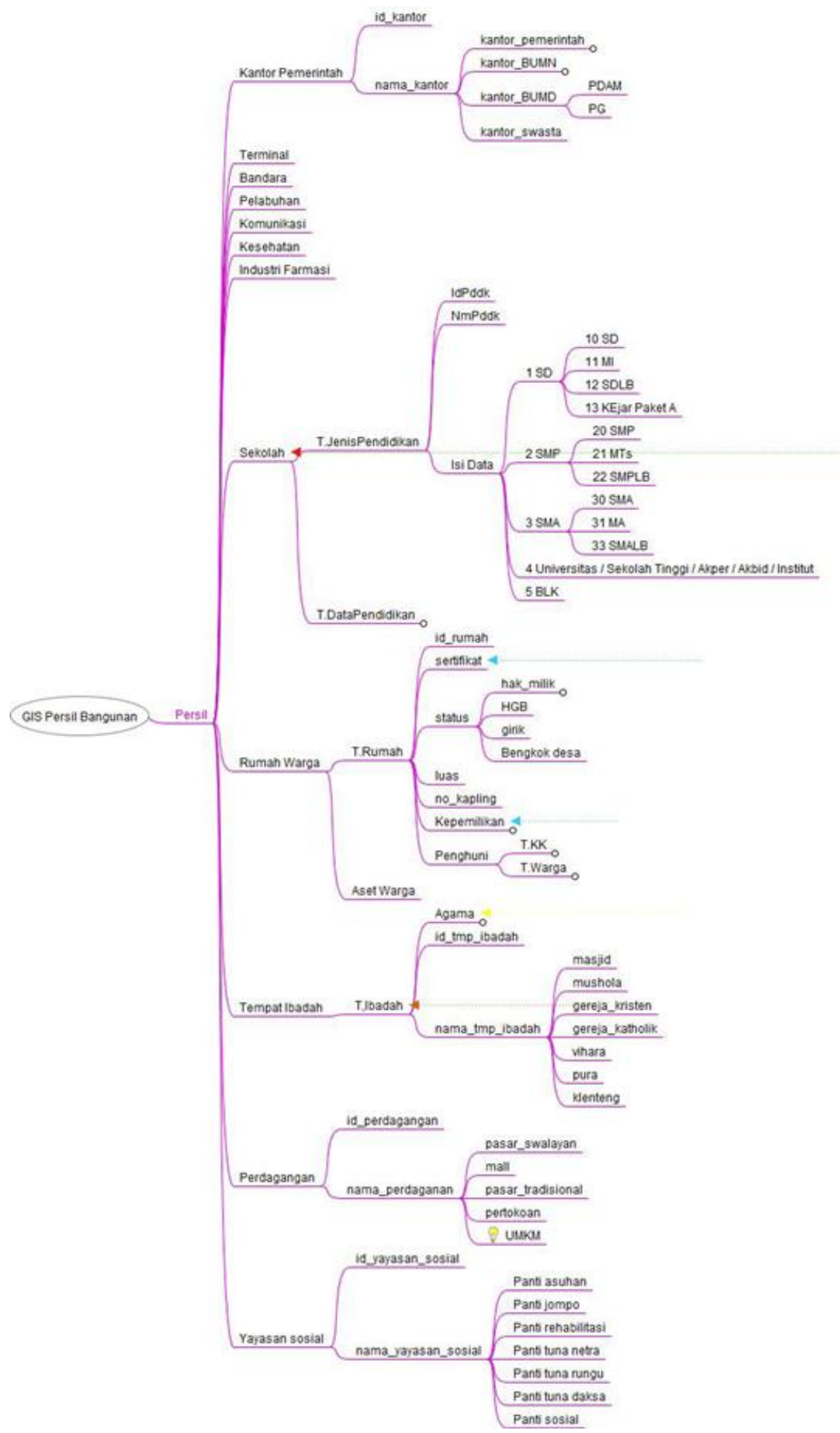

Gambar 7. Alur Freemind GIS Persil Bangunan

\section{KESIMPULAN}

Dari hasil analisis dan perancangan, serta implementasi dan pengujian yang telah dilakukan dapat diambil kesimpulan sebagai berikut :

1. Menghasilkan sistem berbasis web untuk sistem informasi geografis 
yang dapat menginformasikan sebuah data dalam wujud data spasial secara lebih riil.

2. System yang dihasilkan digunakan untuk melakukan pendataan data-data di instansi pemerintahan paling dasar yang secara langsung berinteraksi dengan data dasar yaitu instansi pemerintahan di kelurahan atau desa.

3. System ini bertujuan untuk lebih memudahkan pengupdate-an data yang setiap saat dapat saja berubah.

4. Hasil pengujian system di antaranya pengujian proses login admin, pengujian proses pengelolaan data pendukung, pengujian pengelolaan data master, pengujian pemetaan lahan persil, serta pengujian login pimpinan berhasil dilakukan serta output yang dihasilkan sesuai dengan yang diharapkan.

Meskipun system informasi geografis berbasis web digitasi persil bangunan ini telah berhasil dilaksanakan, system ini masih dapat dikembangkan menjadi jauh lebih baik lagi. Saran yang dapat penulis sampaikan adalah sebagai berikut :

1. Untuk lebih lanjut system ini diharapkan tidak hanya berbasis web, atau dengan menggunakan system operasi android.

2. Harapannya system ini dapat meng-upload data dasar dari kelurahan agar lebih baik dalam penyampaian informasinya, karena dalam system ini masih belum ada.

3. Ke depannya penulis juga mengharapkan pengembangan dari sytem ini terdapat fitur untuk masyarakat agar dapat memberi masukkan atau komentar jika terjadi kesalahan penginformasian tentang data yang telah disajikan.

4. Sytem informasi geografis ini diharapkan tidak hanya diimplementasikan pada satu desa, tetapi dapat diimlementasikan pada seluruh desa.

\section{DAFTAR PUSTAKA}

1) Aliyah, Fie Jannatin. Sistem Informasi Geografis Berbasis Web Mengenai Penyebaran Fasilitas Pendidikan, Perumahan, dan Rumah Sakit di Kota Bekasi.

2) Arief, M. Rudyanto.2011. Pemrograman Web Dinamin menggunakan PHP dan MySQL. Yogyakarta : Penerbit Andi

3) Budiyanto, Eko.2004. Sistem Informasi Geografis Menggunakan MapInfo. Yogyakarta : Penerbit Andi.

4) Gabriel Svennerberg.2010. Beginning Google Maps Api 3. United States.

5) Kendall, Kenneth E dan Kendall, Julie E 2011. Systems Analysis And Design

6) Kristanto, Harianto.2004. Konsep \& Perancangan Database. Yogyakarta : Penerbit Andi.

7) Kupas Tuntas adobe Dreamweeaver CS5 dengan Pemrograman PHP \& $M y S Q L$. Penerbit Andi dan Madcoms

8) Menguasai Pemrograman Web dengan JavaScript 2009. Penerbit Andi

9) PPRI dan PERMENDAGRI TH. 2008 Tentang Desa- KelurahanKecamatan

10) Rismayanda, Esty. 2012. Sistem Informasi Geografis Perumahan Kota Sistem Informasi Geografis Berbasis Web Digitasi Persil Bangunan 


\section{SYSTEMIC}

Vol. 1, No. 1, Agustus 2015, 20-28

Banjarbaru Kalimantan Selatan.

11) Sommerville, Ian. 2009.Software Engineering

12) Sutarman, 2007. Membangun Aplikasi Web dengan PHP \& $M y S Q L$. Yogyakarta : Graha Ilmu

13) Wulandari, Retno.2013. Sistem Informasi Geografis Konfeksi Pada Wilayah Kabupaten Kudus Dengan Memanfaatkan Google Maps Api. 